\title{
Reactive astrocytes undergo M1 microglia/ macrohpages-induced necroptosis in spinal cord injury
}

\author{
Hong Fan ${ }^{1 \dagger}$, Kun Zhang ${ }^{1 \dagger}$, Lequn Shan ${ }^{2}$, Fang Kuang ${ }^{1}$, Kun Chen ${ }^{1}$, Keqing Zhu ${ }^{3}$, Heng Ma ${ }^{4}$, Gong Ju* \\ and Ya-Zhou Wang ${ }^{1 *}$
}

\begin{abstract}
Background: A unique feature of the pathological change after spinal cord injury (SCl) is the progressive enlargement of lesion area, which usually results in cavity formation and is accompanied by reactive astrogliosis and chronic inflammation. Reactive astrocytes line the spinal cavity, walling off the lesion core from the normal spinal tissue, and are thought to play multiple important roles in SCl. The contribution of cell death, particularly the apoptosis of neurons and oligodendrocytes during the process of cavitation has been extensively studied. However, how reactive astrocytes are eliminated following SCI remains largely unclear.

Results: By immunohistochemistry, in vivo propidium iodide (PI)-labeling and electron microscopic examination, here we reported that in mice, reactive astrocytes died by receptor-interacting protein 3 and mixed lineage kinase domain-like protein (RIP3/MLKL) mediated necroptosis, rather than apoptosis or autophagy. Inhibiting receptorinteracting protein 1 (RIP1) or depleting RIP3 not only significantly attenuated astrocyte death but also rescued the neurotrophic function of astrocytes. The astrocytic expression of necroptotic markers followed the polarization of M1 microglia/macrophages after SCl. Depleting M1 microglia/macrophages or transplantation of M1 macrophages could significantly reduce or increase the necroptosis of astrocytes. Further, the inflammatory responsive genes Toll-like receptor 4 (TLR4) and myeloid differentiation primary response gene 88 (MyD88) are induced in necroptotic astrocytes. In vitro antagonizing MyD88 in astrocytes could significantly alleviate the M1 microglia/macrophagesinduced cell death. Finally, our data showed that in human, necroptotic markers and TLR4/MyD88 were coexpressed in astrocytes of injured, but not normal spinal cord.
\end{abstract}

Conclusion: Taken together, these results reveal that after $\mathrm{SCl}$, reactive astrocytes undergo M1 microglia/ macrophages-induced necroptosis, partially through TLR/MyD88 signaling, and suggest that inhibiting astrocytic necroptosis may be beneficial for preventing secondary SCl.

Keywords: Spinal cord injury, Reactive astrocytes, Necroptosis, M1 microglia/macrophage

\section{Background}

One unique pathological change after primarily spinal cord injury (SCI) is the secondary injury, which is characterized by continuous tissue loss, reactive astrogliosis and chronic inflammation, and usually leads to gradual expansion of the lesion center and formation of a spinal cavity

\footnotetext{
* Correspondence: jugong@fmmu.edu.cn; yazhouw@fmmu.edu.cn ${ }^{\dagger}$ Equal contributors

'Department of Neurobiology and Collaborative Innovation Center for Brain Science, School of Basic Medicine, Fourth Military Medical University, Xi'an 710032, China

Full list of author information is available at the end of the article
}

$[1,2]$. Elucidating the mechanisms of tissue loss, particularly nerve cell death is important for preventing the expansion of the lesion area. Previous studies have paid attention to the glutamate-induced apoptosis of neurons and oligodendrocytes within and around the lesion center [3-5]. However, how reactive astrocytes, which are the major component of the glial scar, play diverse roles in SCI [6] and are particularly important in supporting neuronal survival [6], are eliminated remains poorly investigated. Understanding the mechanism of astrocytic death post-SCI may yield new insights into understanding the 
mechanism of secondary SCI and improving functional recovery.

Chronic inflammation plays an essential role in stimulating astrocyte activation and progressive cavitation $[7,8]$. After SCI, inflammation is mainly generated by activated microglia/macrophages, which are constituted by their two phenotypically distinct subpopulations, the proinflammatory M1, and the anti-inflammatory M2 microglia/macrophages [9]. Compared to the immune reaction in peripheral tissue injury, the polarization of microglia/ macrophages post-SCI is M1 predominant and lasts longer [10-12]. Previous study has revealed the apoptosisinducing effects of M1 microglia/macrophages on neurons and oligodendrocytes [11]. Whether and how the activity of M1 microglia/macrophages affects the survival of reactive astrocytes remains unclear.

In the present study, we analyzed the death of reactive astrocytes in mice and human after spinal contusion, and reported that reactive astrocytes die through necroptosis, a type of programmed necrosis for which the molecular mechanisms have been recently unraveled [13], and is induced by M1 microglia/macrophages, partially via TLR/ MyD88 signaling. Our data indicated that blocking the necroptosis of reactive astrocytes might reduce secondary injury and promote functional recovery after SCI.

\section{Results}

Cavity-surrounding reactive astrocytes undergo necrosis rather than apoptosis or autophagy during the progress of secondary $\mathrm{SCI}$

A modified spinal contusion model which was more experimentally consistent was adopted $[14,15]$. Spinal cavity enlarged gradually and reached plateau by 2 weeks post-injury, with reactive astrocytes surrounded at all time points assessed (Fig. 1a). We first tested whether apoptosis or autophagy accounted for the loss of reactive astrocytes during the development of secondary injury. Because immunohistochemistry of GFAP stains primarily processes and seldom cell bodies, we adopted GFAPCreER:ROSA-YFP mice to visualize the cell bodies of astrocytes. Tamoxifen ( $2.5 \mathrm{mg}$ ) was injected for 5 successive days before SCI to label astrocytes by YFP (Fig. 1b). Double-immunostaining of YFP with TUNEL at 5 days post injury (dpi) showed that very rare could YFP/ TUNEL-double positive cells be found, precluding the apoptosis of astrocytes. Double-immunostaining of YFP with autophagic markers showed that in bilateral areas from $400 \mu \mathrm{m}$ rostral and caudal to border of lesion center defined by YFP/GFAP-immunoreactivity (Fig. 1d), approximately $9.8 \%$ of YFP-positive cells were Lamp2apositive, $6.3 \%$ were LC3-positive and $8.1 \%$ were Beclin1-positive (Fig. 1c). These data suggest that in mice, during the process of cavitation, reactive astrocytes may be eliminated by ways other than apoptosis and autophagy.

To test whether reactive astrocytes could undergo necrosis, the third major type of cell death, we performed live-animal propidium iodide (PI)-labeling. Besides within lesion center, PI-labeled cells could be found in areas around the epicenter. PI- and GFAP-positive cells in bilateral areas from $400 \mu \mathrm{m}$ rostral and caudal to border of lesion center defined by GFAP-immunoreactivity were quantified (Fig. 1d). From 3 to 14 dpi, about $80 \%$ of all PI-labeled cells in these regions were GFAP-positive (Fig. 1e). The percent of astrocytes with PI-labeling reached peak at $5 \mathrm{dpi}$ (Fig. 1e). These data indicate that reactive astrocytes around the spinal cavity undergo necrosis during the process of secondary injury.

\section{Necroptosis of reactive astrocytes after $\mathrm{SCl}$}

Necroptosis is a type of programmed necrosis for which the molecular mechanisms have recently been uncovered [16]. Death signals activate an intracellular signaling which is mediated mainly by protein complexes involving receptor-interacting protein 1 (RIP1), receptor-interacting protein 1 (RIP3) and mixed lineage kinase domain-like protein (MLKL), leading to disruption of cell membranes and lysis of cytoplasmic contents [16, 17]. To test whether necroptosis occurs in the reactive astrocytes after SCI, we first examined the expression of RIP3 in mice by Western-blotting. The expression of RIP3 increased significantly from 3 dpi to $7 \mathrm{dpi}$ (Fig. 2a). Immunohistochemistry detected strong RIP3-immunoreactivity around lesion center, with most expressed by GFAP-positive cells (Fig. 2b). Quantification showed that at all time points examined, approximately $80 \%$ of the RIP3-positive cells were GFAP-positive (Fig. 2b), which was consist with the results of PI-labeling (showed by Fig. 1e). OX42-positive, NeuN-positive, and CC-1-positive cells constituted for the remainder of RIP3-positive cells (Fig. 2c). MLKL, another key molecule in execution of necroptosis [18], was also induced by SCI and expressed in reactive astrocytes (Fig. 2d). In addition, HMGB1, a member of high mobility group box protein that normally binds to chromatin and is released by necrotic cells [19], was detected in the cytoplasm of GFAP-positive cells (Fig. 2e), supporting the occurrence of necrosis in astrocytes.

To confirm the necroptosis of astrocytes after SCI, we performed immune-electron microscopic study in spinal tissue within $5 \mathrm{~mm}$ around lesion center at $5 \mathrm{dpi}$ in mice. Astrocytes with focal lysis of cytoplasm and RIP3 immunoreactivity on the cytoplasmic fibrils were frequently found (Fig. 2f). MLKL-immunoreactivity was found both at the cell membrane and within the bundles of cytoplasmic fibrils (Fig. 2g), consistent with its role in penetrating the cell membrane during necroptosis [20]. No apoptoticlike astrocytes were observed. Taken together, these data 


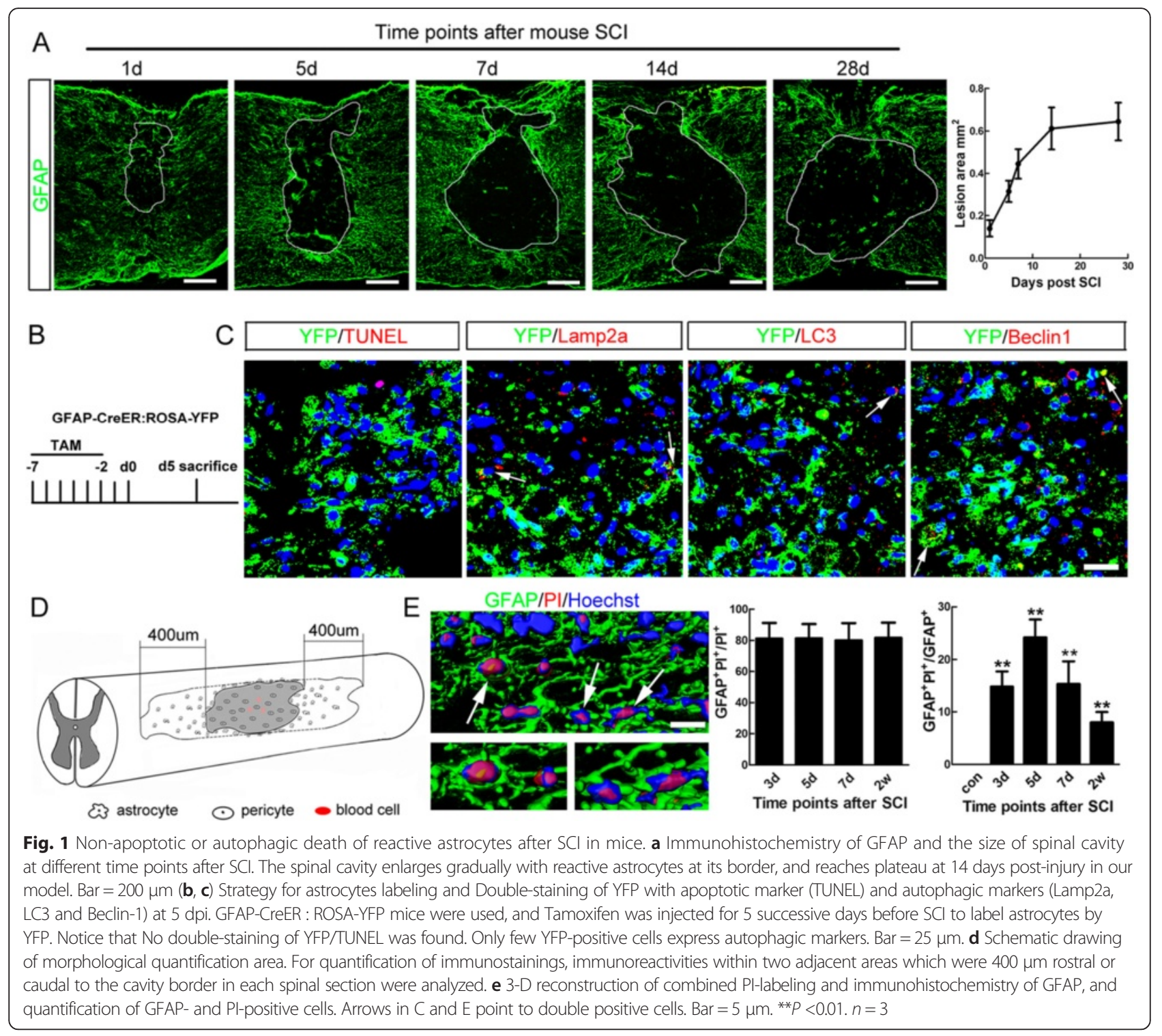

suggested that reactive astrocytes may undergo RIP3/ MLKL-mediated necroptosis after SCI in mice.

\section{In vitro inflammatory stimulation of necroptosis in astrocytes}

We then examined whether necroptosis could be modeled in reactive astrocytes in vitro. Mouse spinal cord astrocytes were cultured and purified as described [21, 22]. Only batches of cells in which the percent of GFAPpositive cells was over $99 \%$ were used for cell death induction (Additional file 1: Figure S1). The cells were challenged with tumor necrosis factor alpha (TNFo) and lipopolysaccharide (LPS) to mimic the inflammatory microenvironment in vivo, and z-VAD, a pan-caspase inhibitor was added to inhibit apoptosis as routinely used by researchers when inducing necroptosis [17, 18]. Forty-eight hours treatment of TNF $\alpha$, LPS and z-VAD
(TLZ) significantly increased the expression of RIP3, MLKL, and cytoplasmic HMGB1, while decreased nucleus levels of HMGB1 (Fig. 3a-d). Upon TLZ treatment, the intracellular level of reactive oxygen species (ROS) and the percent of PI-labeled astrocytes were significantly increased, and intracellular level of ATP significantly decreased (Fig. 3e-i). These data indicate that necroptosis of astrocytes can be induced by TLZ in vitro. Further, Necrostatin-1 (Nec-1), a well-used necroptosis inhibitor that inhibits phosphorylation of RIP1 [23], significantly compromised the increase of RIP3, MLKL, cytoplasmic high mobility group box 1 (HMGB1), intracellular ROS, extracellular ATP and PI-labeling induced by TLZ treatment (Fig. 3a-i), indicating a rescuing effect of Nec-1 on astrocyte death. Because Nec-1 also inhibits indoleamine-2,3-dioxygenase (IDO) [24], we then used RIP3 ${ }^{-/-}$astrocytes to confirm the occurrence of 


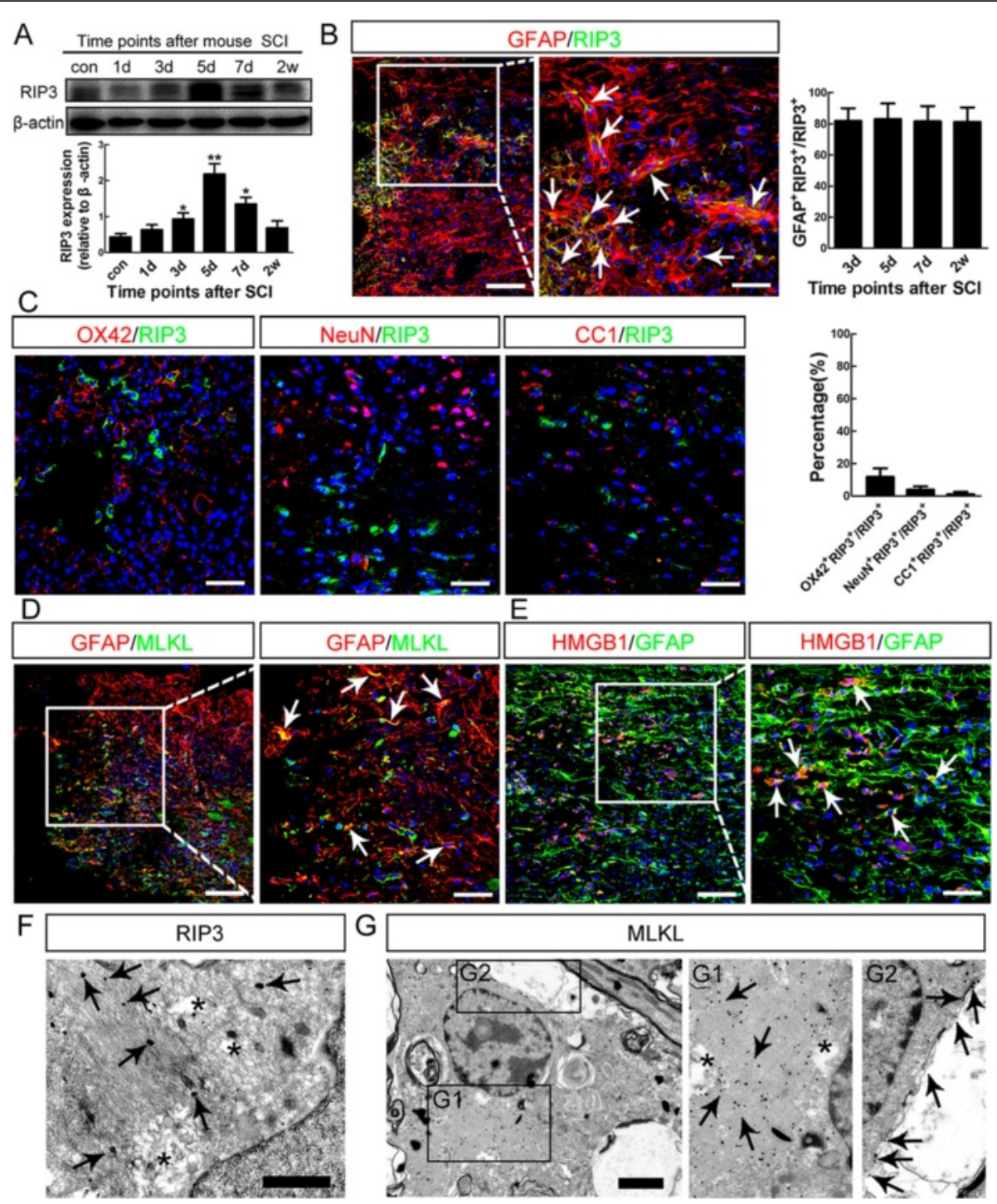

Fig. 2 Necroptosis of reactive astrocytes in injured mice spinal cord. a Western-blotting of RIP3 after SCI. Notice that the increase of RIP3 from 3 to 7 days post-injury. ${ }^{*} P<0.05$, ${ }^{*} P<0.01 . n=3$. b Double staining and quantification of RIP3 and GFAP at 5 days post-injury. Notice that at all time points, most RIP3-positive cells were GFAP-positive. Arrows points to RIP3/GFAP double-positive cells. Bar $=100 \mu \mathrm{m}$. Bar in insert $=50 \mu \mathrm{m}$. c Double-staining and quantification of RIP3 with OX42, NeuN and CC1. Notice that micoglia, neurons and oligodendrocytes account for a small portion of RIP3-positive cells. Bars $=50 \mu \mathrm{m}$. d, e Double staining of GFAP with MLKL and HMGB1. Many astrocytes around lesion center express MLKL and cytoplasmic HMGB1, shown by arrows. Bars $=100 \mu \mathrm{m}$. Bars in inset $=50 \mu \mathrm{m}$. $\mathbf{f}$ Immuno-eletron microscopic study of RIP3. Notice the focal cytoplasmic lysis of astrocyte (asterisks) and localization of RIP3 immunoreactivity on glial fibrils (arrows). Bar = 1 um. $\mathbf{g}$ Immuno-eletron microscopic study of MLKL. Notice the fibrils (arrows in G1) and membrane localization (arrows in G2) of MLKL. Focal cytoplasmic lysis was shown by asterisks. Bar $=2 \mu \mathrm{m}$

astrocytic necroptosis. The effects of TLZ on ROS production, ATP level and PI-permeability in wild-type astrocytes were significantly abolished in $\mathrm{RIP}^{-/-}$astrocytes (Fig. 3e-i). These data demonstrated the necroptosis of mouse astrocytes in vitro.

Inhibiting necroptosis rescues both the death and neurotrophic phenotype of reactive astrocytes after $\mathrm{SCl}$ We next examined the effects of inhibiting necroptosis on the survival of astrocytes after SCI. Five successive days of treatment by $\mathrm{Nec}-1$ significantly decreased the percent of PI-positive astrocytes and the expression of RIP3, MLKL and HMGB1 in areas surrounding lesion center (defined as Fig. 1c), as compared to PBS control (Fig. 4a, b). RIP3 ${ }^{-1-}$ mice showed a significant decrease of PI-labeled astrocytes at $5 \mathrm{dpi}$, as compared to wild type mice (Fig. 4c). The expression of MLKL and HMGB1 was also significantly lower in injured $\mathrm{RIP}^{-/-}$spinal cord as compared to wild-type control (Fig. 4d). These data 

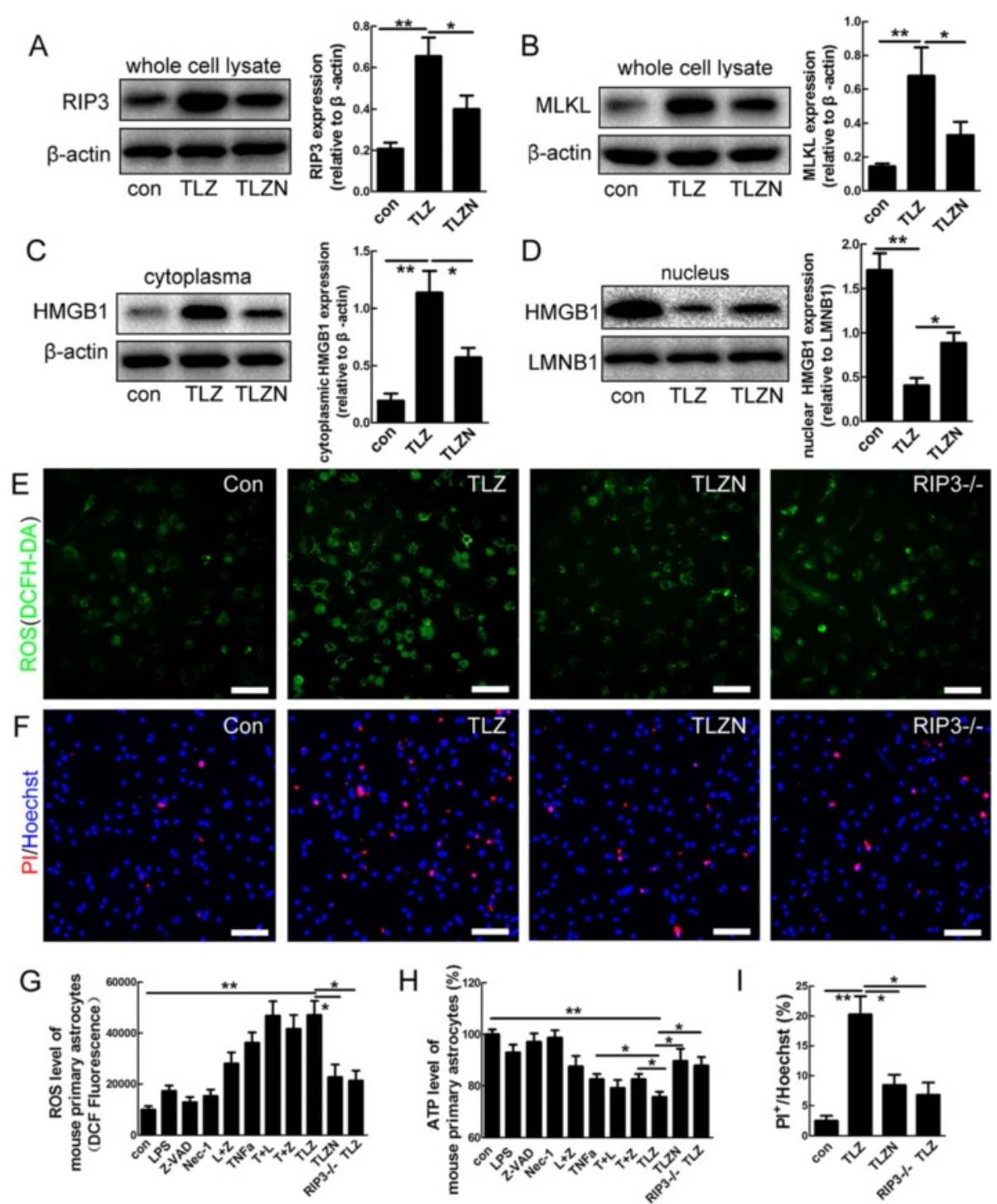

Fig. 3 Necroptosis of mouse spinal cord astrocytes in vitro. $\mathbf{a}$, $\mathbf{b}$ Western-blotting of RIP3 and MLKL in control, TLZ (TNFa, LPS and Z-VAD), TLZN (TLZ plus Nec-1). Notice that TLZ significantly increased the expression of RIP3 and MLKL. This effect was significantly suppressed by Nec-1. ${ }^{* *} P<0.01,{ }^{*} P<0.05 . n=3$. c, d Western-blotting of cytoplasmic and nuclear HMGB1 in control, TLZ or TLZN-treated astrocytes. Notice that TLZ significantly increased cytoplasmic HMGB1, but decreased nuclear HMGB1. The effects of TLZ on HMGB1 were blocked by Nec-1. e ROS staining in control, TLZ treated, TLZN treated and $\mathrm{RIP3}^{-/}$astrocytes. $\mathbf{f} \mathrm{Pl}-$-staining in control, TLZ treated, TLZN treated and RIP3 ${ }^{-/-}$astrocytes. $\mathbf{g}, \mathbf{h}$ Quantification of intracellular ROS and ATP levels in astrocytes under various conditions. i Percentages of PI-positive cells in TLZ treated, TLZN treated astrocytes and TLZN treated RIP3 ${ }^{-/-}$astrocytes. Bars in (e), $\mathrm{F}=50 \mu \mathrm{m} .{ }^{*} P<0.01 .{ }^{*} P<0.05 . n=3$

indicate that inhibiting necroptosis after SCI could effectively prevent the death of astrocytes.

Because astrocytes are well known for their supportive roles in neuronal survival and neurons around the lesion center die after SCI, we then tested whether necroptosis could affect neurotrophic function of reactive astrocytes. Conditioned medium (CM) of normal astrocytes, TLZ treated necroptotic astrocytes, and necroptosis inhibited astrocytes which was treated by TLZ plus Nec-1 (TLZN) were used to treat primary cultured neurons. Twentyfour hours later, more TUNEL-positive neurons were observed in cells treated by $\mathrm{CM}$ of necroptotic astrocytes in comparison with those in cells treated by $\mathrm{CM}$ of normal astrocytes (Fig. 5a). A significantly less TUNELpositive neurons were observed in cells treated by $\mathrm{CM}$ of TLZN treated astrocytes, as compared to that of TLZ treated astrocytes (Fig. 5a). Further, we examined the effects of necroptosis inhibition on the expression of glial cell line-derived neurotrophic factor (GDNF) by reactive astrocytes after SCI. Both Nec-1 and RIP3 depletion significantly enhanced the expression of GDNF by reactive astrocytes (Fig. 5b, c). We then measured the number of 

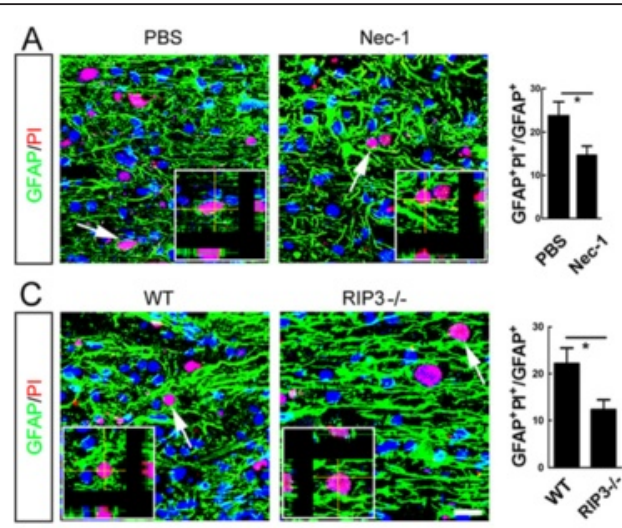

RIP3-1-
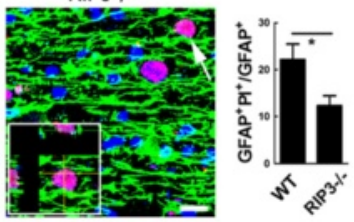

B
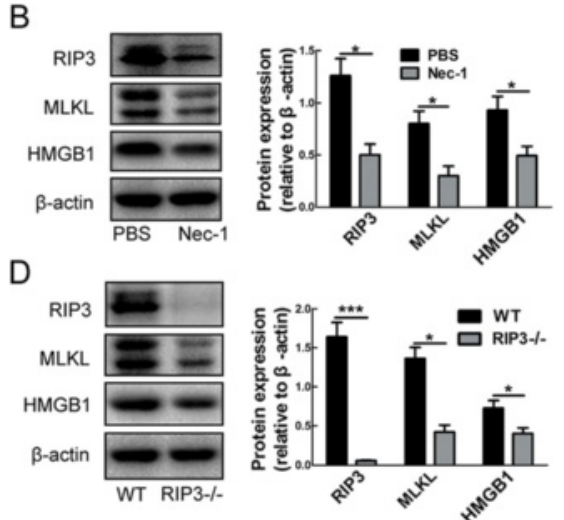

Fig. 4 Effects of necroptosis inhibition on astrocyte death after SCI in mice. a Combination of PI-labeling with immunohtistochemistry of GFAP in mice treated with PBS or Nec-1 at 5 days post-injury. Nec-1 significantly reduced the percent of PI-positive astrocytes. Bar $=50 \mu \mathrm{m}$. ${ }^{*} P<0.05$. $n=3$. $\mathbf{b}$ Western-blotting of RIP3, MLKL and HMGB1 in spinal cord of PBS treated or Nec-1 treated mice at 5 days post-injury. Nec-1 significantly inhibited the expression of RIP3, MLKL and HMGB1, as compared to PBS control. ${ }^{*} P<0.05 . n=3$. c Combination of PI-labeling with immunohtistochemistry of GFAP in wild-type (WT) and RIP3 ${ }^{-/-}$mice. RIP3 depletion significantly reduced the percent of PI-positive astrocytes. Bar $=50 \mu \mathrm{m}$. ${ }^{*} P<0.05$. $n=3$. $\mathbf{d}$ Western-blotting of RIP3, MLKL and HMGB1 in spinal cord of WT and RIP3 ${ }^{-/-}$mice. RIP3 mutation significantly reduced the SCI-induced expression of RIP3, MLKL and HMGB1. ${ }^{* *} P<0.001,{ }^{*} P<0.05 . n=3$

neurons in areas $400 \mu \mathrm{m}$ rostral and caudal to the spinal cavity at $14 \mathrm{dpi}$ after 7 days treatment by Nec-1 or in $\mathrm{RIP}^{-/-}$mice, which were thought to undergo apoptosis during secondary injury. The results showed a significant increase of NeuN-positive cells as well as a smaller size of spinal cavity in Nec-1 treated and $\mathrm{RIP}^{-/-}$mice (Fig. $5 \mathrm{~d}$, e). Taken together, these data suggest that inhibiting necroptosis after SCI not only attenuates astrocyte death but also rescues the neurotrophic function of reactive astrocytes, thereby promoting adjacent neuronal survival.

\section{Induction of necroptosis of reactive astrocytes by M1 microglia/macrophages}

As inflammatory factors can induce astrocytic necroptosis in vitro and M1 microglia/macrophages has been thought to be the major source of toxic inflammatory factors after SCI [12], we hypothesized that M1 microglia/macrophages might induce astrocytic necroptosis after SCI. Western-blotting showed that the expression of inducible nitric oxide synthase (iNOS), a commonly used marker for M1 microglia/macrophages, increased quickly from 1 day and peaked at 3 day post-SCI. The expression of MLKL and HMGB1 increased gradually and peaked at $5 \mathrm{dpi}$, just following the increase of iNOS (Fig. 6a). To directly investigate the effects of M1 microglia/macrophages on astrocytes, we polarized primarily cultured microglia/macrophages toward either M1 or M2 phenotype, and stimulated astrocytes with conditioned medium collected from MO (normal cultured microglia/macrophages), M1, and M2 microglia/ macrophages. The polarization of microglia or macrophages was confirmed by the expression of iNOS and arginase 1, a typical marker for M2 microglia/macrophages
(Additional file 2: Figure S2). All three CMs increased the expression of RIP3, MLKL and HMGB1 in cultured astrocytes. Of note, CM of M1 microglia/macrophages (M1 $\mathrm{CM}$ ) showed the strongest induction of these necroptosis markers (Fig. 6b, Additional file 3: Figure S3). In addition, intracellular ATP was significantly decreased, and the number of PI-labeled cells increased in astrocytes treated by M1 CM (Fig. 6c, d).

To investigate the death-inducing effects of M1 microglia/macrophages on astrocytes in vivo, we depleted M1 microglia by administration of gadolinium chloride $\left(\mathrm{GdCl}_{3}\right)$ in the lesion site as described [25], which induces apoptosis of inflammatory macrophages via competitive inhibition of $\mathrm{Ca}^{2+}$ mobilization and damage to plasma membranes [26, 27]. Depletion of M1 microglia/ macrophages was confirmed by reduced expression of iNOS (Additional file 4: Figure S4). In comparison with $\mathrm{PBS}$ control, $\mathrm{GdCl}_{3}$ treatment significantly reduced the expression of RIP3, MLKL and HMGB1, and decreased the percent of PI-labeled astrocytes within bilateral regions $400 \mu \mathrm{m}$ rostral and caudal to the epicenter (Fig. 7a, b). Consistently, smaller spinal cavity at $14 \mathrm{dpi}$ and better locomotion recovery from 6 dpi were observed in $\mathrm{GdCl}_{3}$ treated mice (Fig. 7c, d).

To further confirm the effects of M1 microglia/macrophages on astrocyte death and spinal cavity, we prepared primary cultured macrophages from bone marrow, and transplanted M0 and M1-polarized macrophages into the injured spinal cord. Transplantation of M1 macrophages resulted in a dramatic increase of RIP3, MLKL and HMGB1 expression and the number of PI-labeled astrocytes, while transplantation of M0 macrophages only showed minor effects, as compared to Dulbecco's 


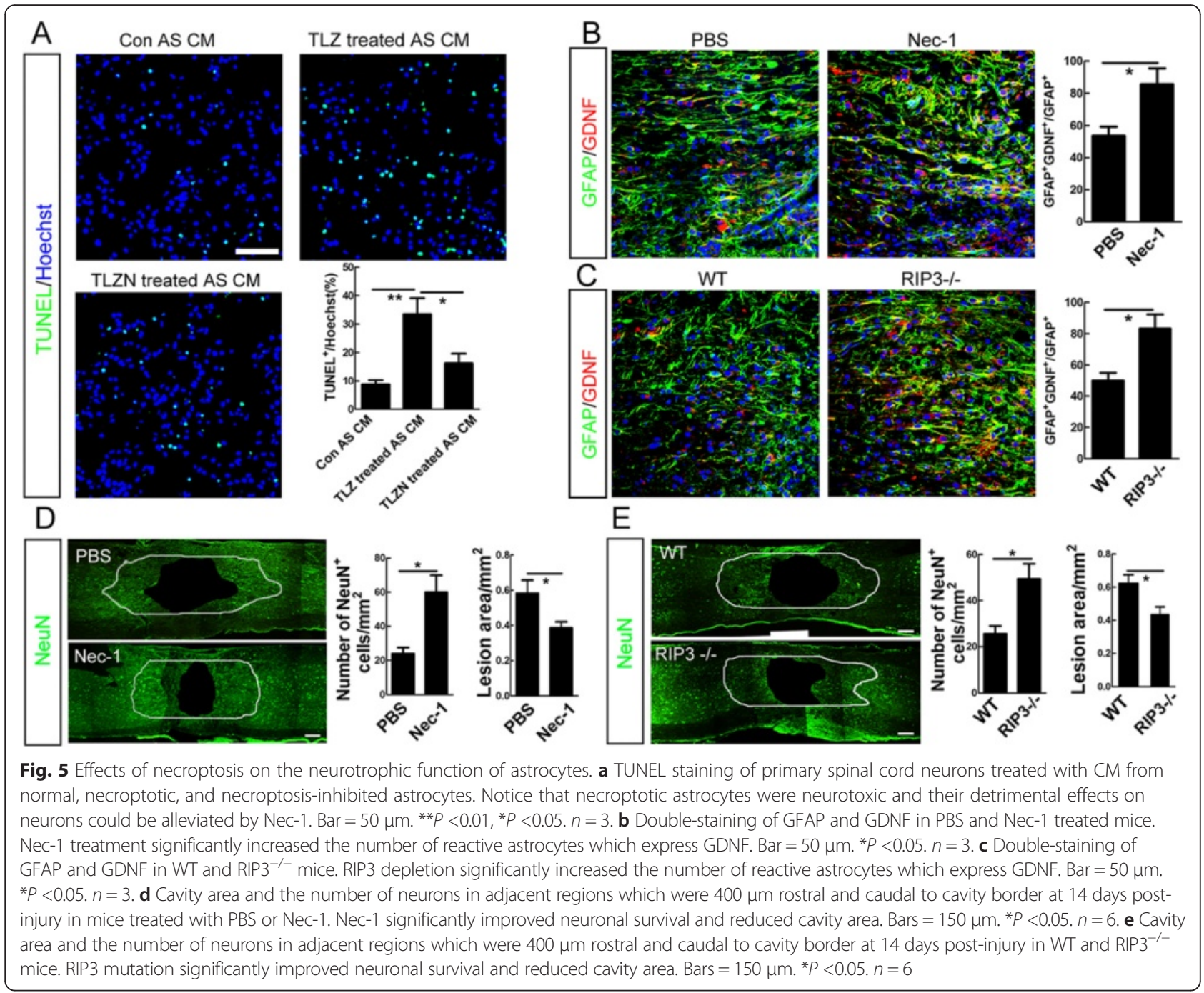

Modified Eagle's Medium (DMEM) control (Fig. 7e, f). Likewise, the spinal cavity was significantly larger at 14 $\mathrm{dpi}$, and the locomotion recovery worse from $5 \mathrm{dpi}$ in M1 macrophage-transplanted mice (Fig. 7g, h). Taken together, these data indicate that M1 micoglia/macrophages play an inductive role in the necroptosis of astrocytes after SCI.

\section{Involvement of astrocytic TLR/MyD88 signaling in M1 microglia/macrophage-induced necroptosis}

As showed above, LPS was required for the in vitro induction of astrocytic necroptosis. We thus speculated that toll-like receptors (TLR) and their downstream molecules might be involved in the M1 microglia/macrophages-induced astrocytic necroptosis. Among TLRs members, TLR2 and TLR4 respond to same type of stimulus and have been thought to be involved in astrocyte activation $[28,29]$. Double-staining of GFAP with TLR2 or TLR4 showed that only a minor portion of reactive astrocytes surrounding spinal cavity express TLR2, while most reactive astrocytes express TLR4 (Fig. 8a, b). We then focused on the expression of TLR4 and the intracellular adaptor molecule MyD88. The immunoreactivity of TLR4 overlapped very well with that of RIP3 in the injured mouse spinal cord (Fig. 8c). MyD88 was also highly expressed in reactive astrocytes (Fig. 8d), suggesting that TLR4/MyD88 signaling was activated in necroptotic astrocytes after SCI. In vitro, TLZ treatment stimulated a dramatic increase of TLR4 and MyD88, as well as a moderate increase of TLR2, in astrocytes (Fig. 8e, Additional file 5: Figure S5). A TAT-tagged MyD88 inhibitory peptide which could block the homodimerization of MyD88 was added into culture medium of astrocytes to antagonize the function of MyD88 [30]. The MyD88 inhibitory peptide significantly suppressed the increase of RIP3 and PI-labeling in astrocytes induced by TLZ treatment (Fig. $8 \mathrm{f}-\mathrm{h}$ ), suggesting that TLR/MyD88 may be required for the activation of necroptotic signaling in astrocytes. 


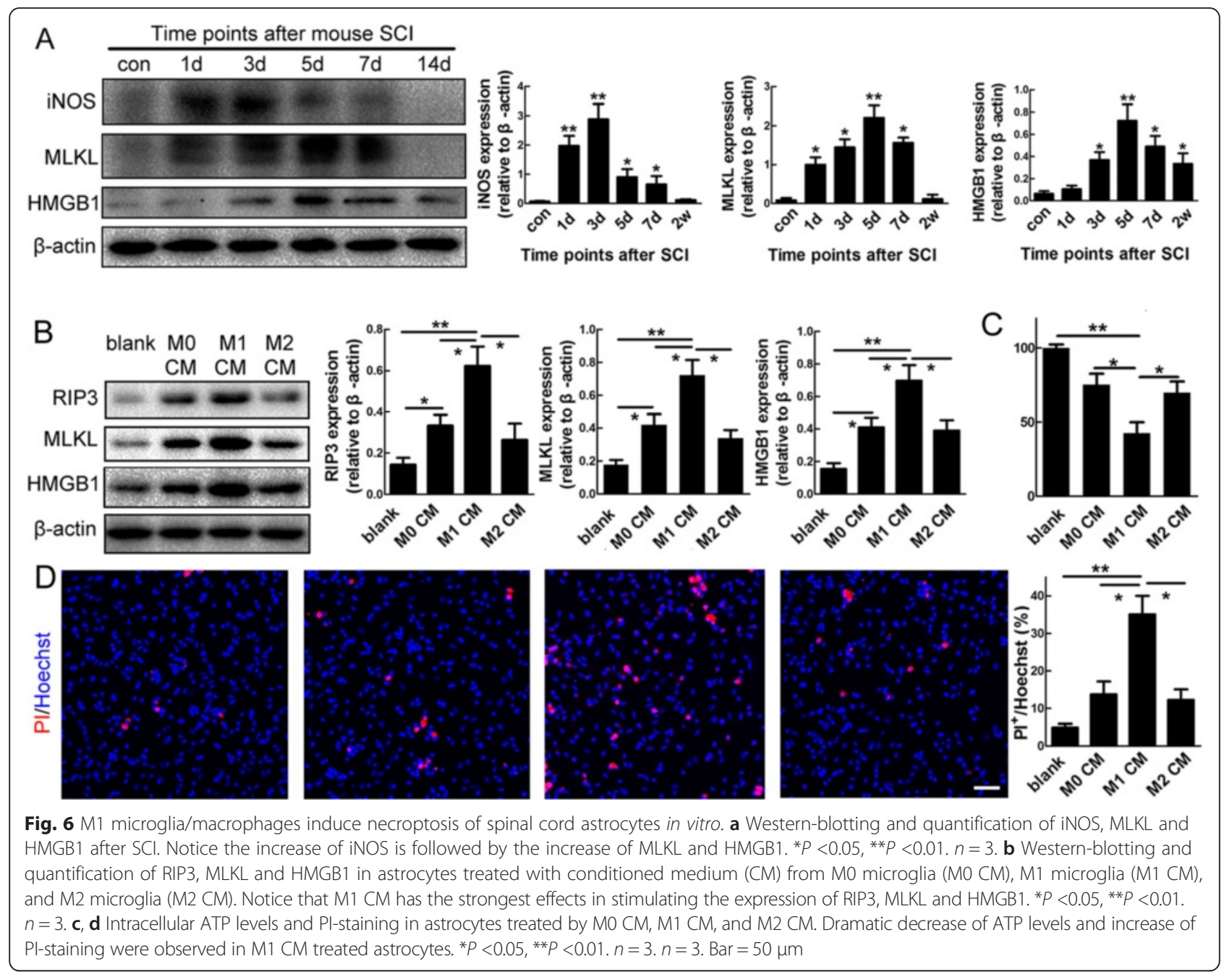

We then examined the effects of M1 microglia/macrophages on the expression of TLR4 and MyD88 in astrocytes. Conditioned medium from M1 macrophages significantly increased the expression TLR4 and MyD88 (Fig. 8i). The MyD88 inhibitory peptide effectively blocked the induction of RIP3 by M1 macrophages (Fig. 8j). In vivo, $\mathrm{GdCl}_{3}$ treatment significantly decreased the percent of astrocytes expressing TLR4 or MyD88 by approximately 39 and $47.4 \%$, respectively (Fig. 8k, l). In contrast, transplantation of M1 macrophages significantly increased the number of astrocytes expressing TLR4 and MyD88, compared to the DMEM control (Fig. 8k, l). These data indicate that in mice, TLR/MyD88 signaling may be involved in the M1 microglia/macrophage-induced necroptosis of astrocytes.

Expression of necroptotic markers and TLR4/MyD88 in astrocytes of injured human spinal cord

The above experiments in mice indicated that after SCI, reactive astrocytes died by necroptosis, which was induced by M1 microglia/macrophages, partially through
TLR/MyD88 mediated signaling. We next tested whether similar pathological changes could occur in human after SCI. Immunohistochemistry showed a very weak expression of RIP3 and MyD88, mainly by astrocytes in normal human spinal cord (Fig. 9a, e). No expression of MLKL, HMGB1 and TLR4 was detected in normal human spinal cord (data not shown). However, after SCI, strong RIP3-, phosphorylated-MLKL- (pMLKL) and HMGB1-immunoreactivities were detected in GFAPpositive cells around the lesion center in one patient at 5 dpi (Fig. 9b-d). Interestingly, TLR4- and MyD88immunoreactivities were also detected in RIP3-positive or GFAP-positive cells (Fig. 9f-h). Similar expression patterns of RIP3, pMLKL, HMGB1, TLR4 and MyD88 were observed in another patient at $15 \mathrm{dpi}$ (data not shown). These results suggested that in human, reactive astrocytes may also undergo necroptosis after SCI.

\section{Discussion}

Necrosis has been traditionally thought to account for the acute cell loss post-SCI and be uncontrollable [31]. 

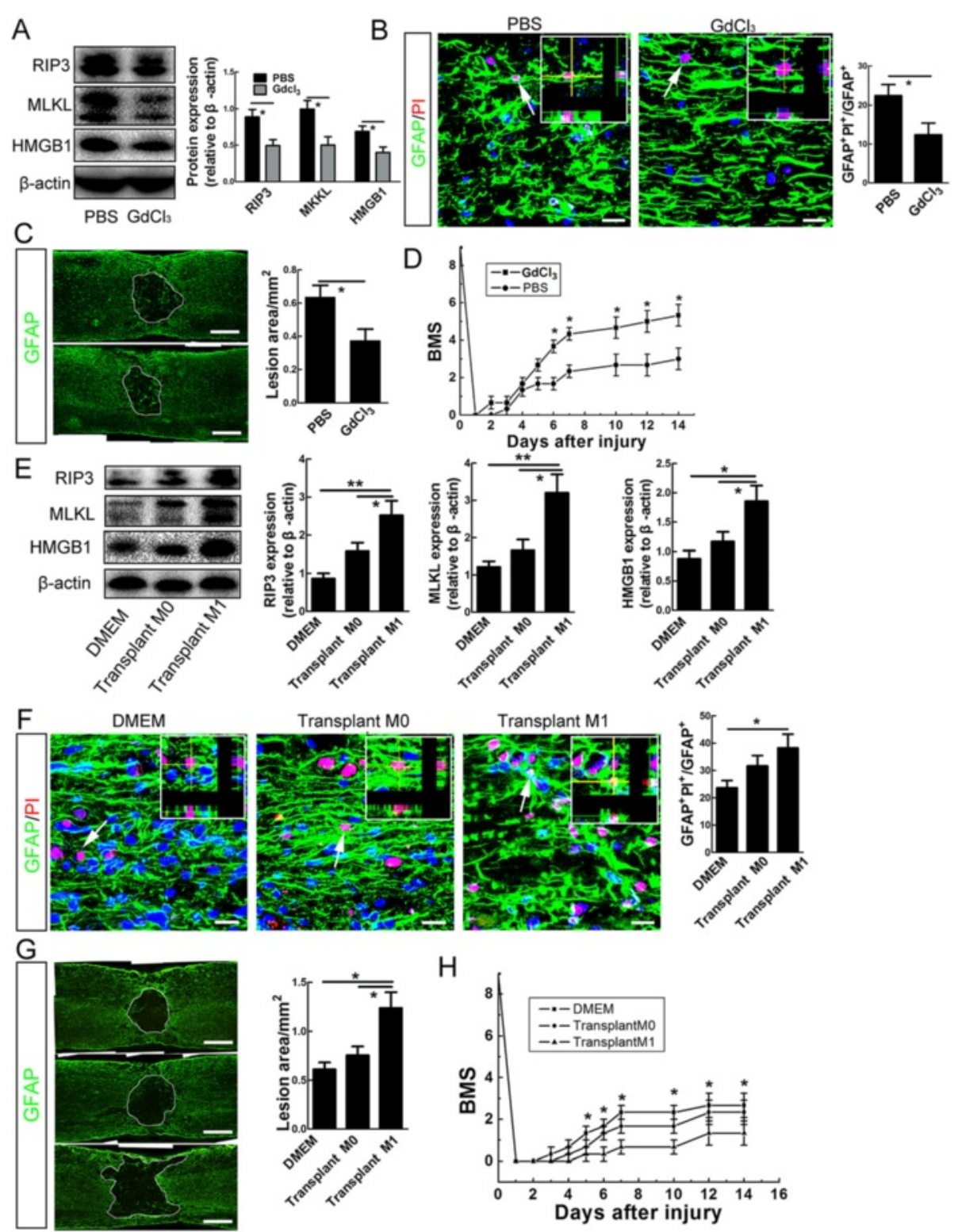

Fig. 7 Effects of depleting M1 microglia/macrophages or transplantation of M1 macrophages on astrocytic death and functional recovery. a Western-blotting ofRIP3, MLKL and HMGB1 at 5 days post-injury in $\mathrm{GdCl}_{3}$ - or PBS- treated mice. $\mathrm{GdCl}_{3}$ treatment significantly blocked the induction of RIP3, MLKL and HMGB1 by SCI. ${ }^{*} P<0.05 . n=3$. b Double-staining of GFAP and PI at 5 days post-injury in $\mathrm{GdCl}_{3}$ or PBS treated mice. $\mathrm{GdCl}_{3}$ treatment significantly reduced the percent of Pl-labeled astrocytes. Bar $=50 \mu \mathrm{m} .{ }^{*} P<0.05 . n=3$. c , d Quantification of cavity area at 14 days post-injury and evaluation of locomotion recovery in $\mathrm{GdCl}_{3}$ and PBS treated mice. $\mathrm{GdCl}_{3}$ treatment significantly reduced cavity size and enhanced functional recovery. BMS stands for for Basso mouse scale. Bars $=200 \mu \mathrm{m}$. ${ }^{*} P<0.05 . n=3$. e, f Western-blotting of RIP3, MLKL and HMGB1, and double-staining of GFAP and PI in injured spinal cord at 5 days after transplantation of M0 macrophages or M1 macrophages. M1 macrophages significantly increased the expression of RIP3, MLKL and HMGB1, and the number of PI-labeled astrocytes, as compared to DMEM control. Bar $=50 \mu \mathrm{m}$. ${ }^{*} P<0.01,{ }^{*} P<0.05 . n=3 . \mathbf{g}, \mathbf{h}$ Quantification of cavity area and locomotion recovery after transplantation of DMEM, M0 macrophages or M1 macrophages. Transplantation of M1 macrophages significantly expanded the area of spinal cavity and impeded function recovery. BMS stands for for Basso mouse scale. ${ }^{*} P<0.05 . n=3$. Bars $=200 \mu \mathrm{m}$

Recent progress in the field of cell death has identified a novel type of programmed necrosis, necroptosis [23], and unveiled the underlying molecular mechanism, which is mediated by an intracellular RIP1/3/MLKL signaling cascade [32, 33], thereby offering an opportunity for re- examining necrosis after SCI. Previous studies have reported protective effects of Nec-1 on SCI in rats without knowing the cell types that Nec-1 targets [34, 35]. Our in vivo PI-labeling showed that astrocyte was the major type of cells that undergo necrosis after SCI. The 


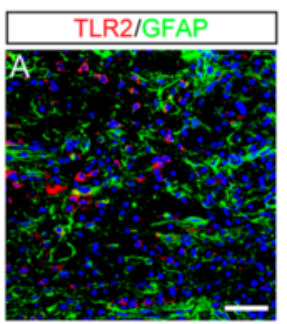

E
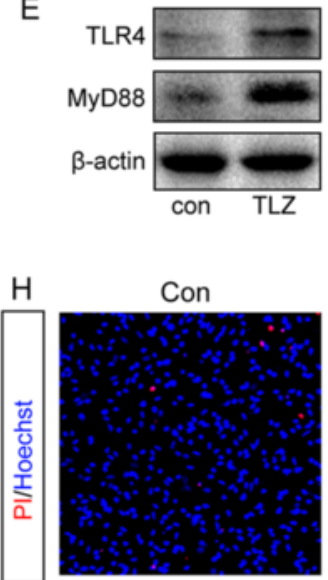

I

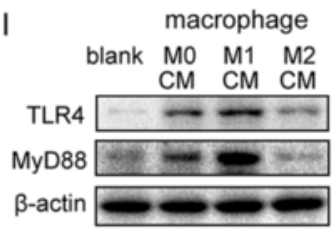

DMEM

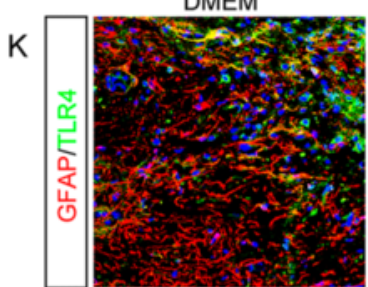

L

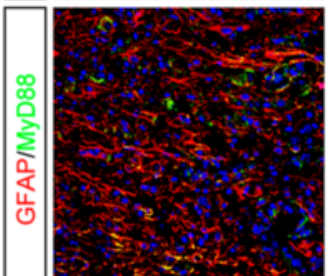

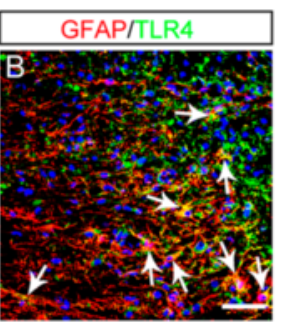

$\mathrm{F}$

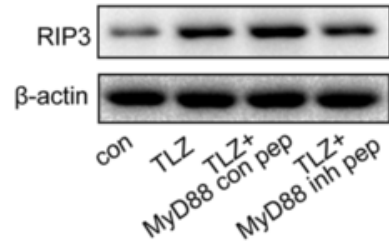

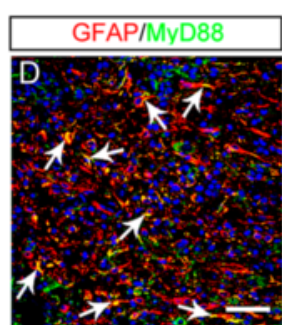

G

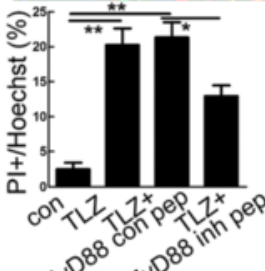

TLZ

TLZ+MyD88 con pep

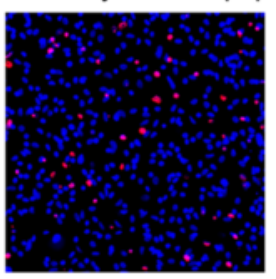

TLZ+MyD88 inh pep
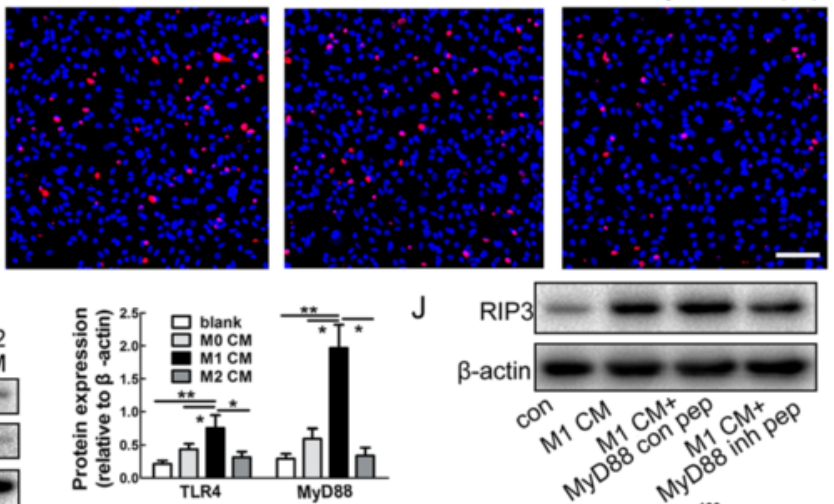

$\mathrm{GdCl}_{3}$

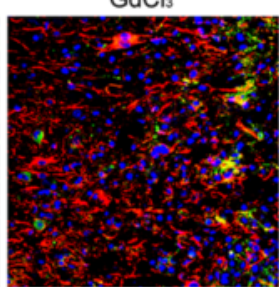

Transplant M1
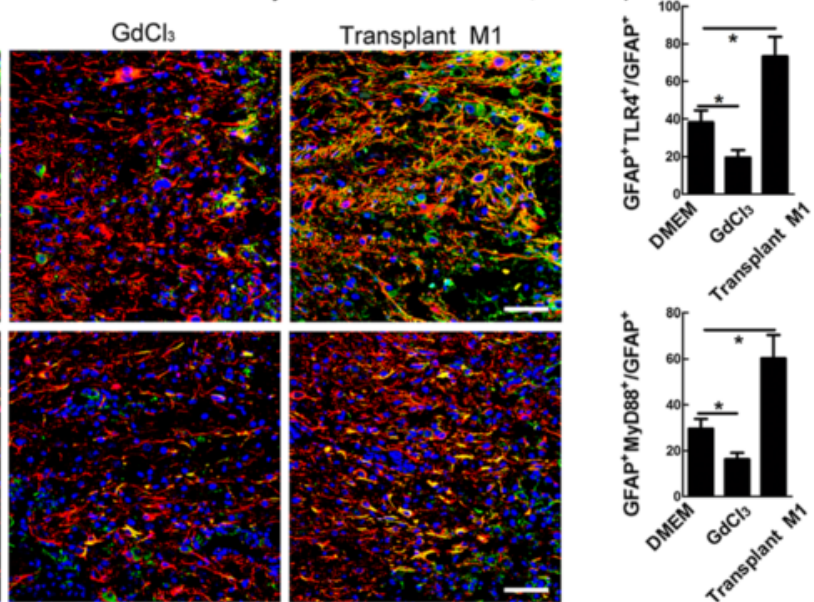

Fig. 8 Involvement of TLR4/MyD88 signaling in M1 microglia/macrophages-induced necroptosis of astrocytes. $\mathbf{a}$, b Double-staining of GFAP with TLR2 or TLR4. Notice that many GFAP-positive cells around the lesion center express TLR4 (arrows). Bars $=50 \mu \mathrm{m}$. c, $\mathbf{d}$ Double-staining of RIP3/TLR4 and MyD88/ GFAP. Notice that there are many RIP3/TLR4 and MyD88/GFAP double-positive cells (showed by arrows) in the injured mouse spinal cord. Bars $=50 \mu \mathrm{m}$. e Western-blotting of TLR4 and MyD88 in cultured astrocytes after treatment with TLZ or vehicle control. TLZ treatment dramatically induced the expression of TLR4 and MyD88. $\mathbf{f}-\mathbf{h}$ Western-blotting of RIP3 and PI-staining in astrocytes treated with vehicle control, TLZ, TLZ plus control peptide (MyD88 con pep), and TLZ plus a MyD88 inhibitory peptide (MyD88 inh pep). Notice that MyD88 inhibitory peptide significantly suppressed the effects of TLZ on the expression of RIP3 and MLKL and PI-labeling. ${ }^{*} P<0.01,{ }^{*} P<0.05 . n=3$. Bar $=50 \mu \mathrm{m}$. i Western-blotting of TLR4, MyD88 in normally cultured astrocytes, and astrocytes treated with $\mathrm{MO} C \mathrm{CM}, \mathrm{M} 1 \mathrm{CM}$, and $\mathrm{M} 2 \mathrm{CM}$ from microglia/macrophages. Notice that M1 CM significantly increased the expression of TLR4 and MyD88. ${ }^{*} P<0.01,{ }^{*} P<0.05 . n=3$. $\mathbf{j}$ Western-blotting of RIP3 in astrocytes treated with DMEM control, M0 CM, M1 CM, and M2 CM. k, I Double-staining of GFAP with TLR4 and MyD88 at 5 dpi in DMEM injected, GdCl ${ }_{3}$ treated or M1 macrophages transplanted mice. Notice that $\mathrm{GdCl}_{3}$ treatment significantly decreased, while transplantation of $\mathrm{M} 1$ macrophages significantly increased the percent of astrocytes expressing TLR4 or MyD88 in adjacent regions which were $400 \mu \mathrm{m}$ rostral and caudal to cavity border. ${ }^{*} P<0.05$. Bars $=50 \mu \mathrm{m} . n=3$ 


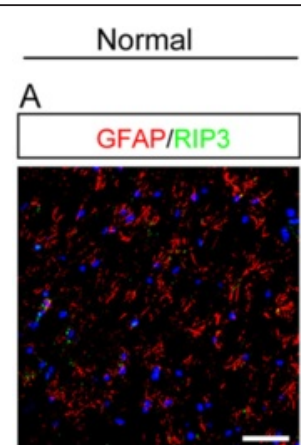

E

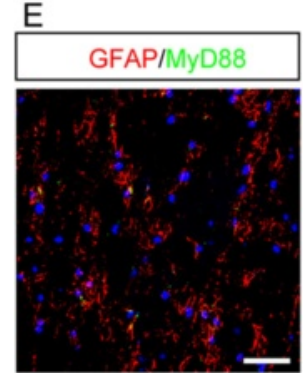

$\mathrm{SCl}$

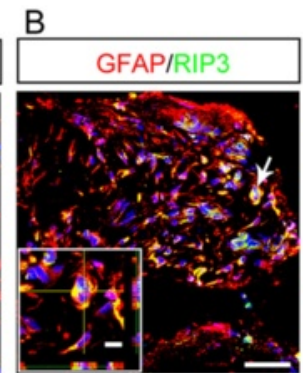

$\mathrm{F}$

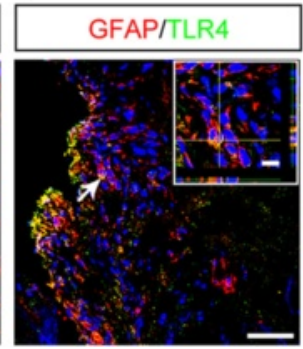

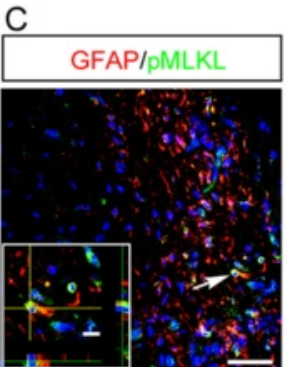

G

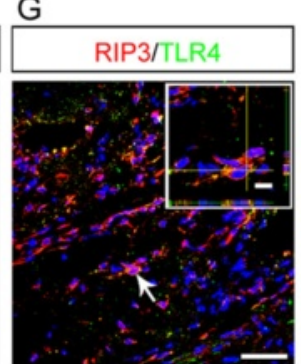

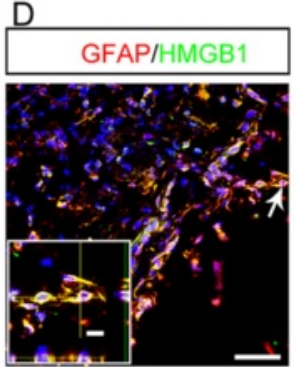

H

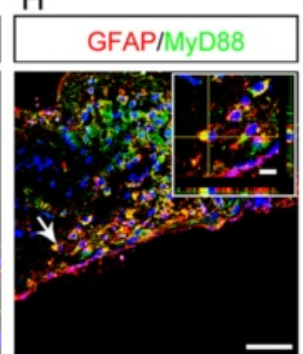

Fig. 9 Expression of necroptotic markers and TLR/MyD88 by astrocytes in injured human spinal cord. a Double-staining of GFAP with RIP3 in uninjured human spinal cord. Notice the very weak expression of RIP3. Bar $=50 \mu \mathrm{m}$. b-d Representative images of double-staining of GFAP with RIP3, pMLKL and HMGB1 in human spinal cord at 5 days post-injury. Notice the co-localization of RIP3, pMLKL and HMGB1 with GFAP. Bars $=50 \mu$ m. e Double-staining of GFAP with MyD88 in uninjured human spinal cord. Notice the very weak expression of MyD88. Bar $=50 \mu m$. $\mathbf{f}-\mathbf{h}$ Representative images of double-staining of TLR4/RIP3, TLR4/GFAP and GFAP/MyD88 in human spinal cord at 5 and 15 days post-injury. Notice the co-localization of TLR4 with RIP3 and GFAP, and MyD88 with GFAP. Bars $=50 \mu \mathrm{m}$

ultrastructural localization of RIP3 and MLKL on the cytoplasmic glial fibrils confirmed the astrocytic necroptosis in SCI. Interestingly, PI-positive astrocytes persisted for 2 weeks in injured spinal cord, indicating that chronic necrosis may be an important contributor of cavity formation post-SCI. We recently reported that microglia/macrophages undergo necroptosis after SCI [36], which was consistent with our observation that RIP3 was primarily expressed by reactive astrocytes, and secondarily expressed by microglia/macrophages (Fig. 2b, c). Considering the fact that inflammation plays critical roles in the cavity formation after SCI, the beneficial effects of necroptosis inhibition on SCI may be results from the protection of astrocytes, microglia/ macrophages, as well as other cells.

The innate immune reaction produced by microglia/ macrophages has been demonstrated to contribute to the cavity formation and enlargement after SCI [7]. The destructive effects of activated microglia/macrophages were largely attributed to their M1 sub-group, which was activated quickly after SCI and expressed high levels of pro-inflammatory cytokines, including the wellstudied necroptosis inducing factor TNF $\alpha$ [23, 37]. It is therefore reasonable to speculate a link between M1 micorglia/macrophages and astrocyte death after SCI, which has been poorly investigated. Our data showed that in vitro, conditioned medium of M1 microglia/ macrophages could induce necroptosis of astrocytes. In vivo, depletion of M1 microglia/macrophages by $\mathrm{GdCl}_{3}$ or transplantation of M1 macrophages can reduce or enhance necroptosis of astrocytes respectively. These results indicated a critical role of M1 microglia/macrophages in inducing the necroptosis of astrocytes after SCI. Considering that $\mathrm{GdCl}_{3}$ also affects neutrophils [38], which are abundant in the injury epicenter after SCI, and that iNOS can also be expressed by neutrophils [39]. The beneficial effects of $\mathrm{GdCl}_{3}$ treatment may also be contributed by the inhibition of neutrophils.

Although the identities of death factors released by M1 microglia/macrophages remain unclear, our data showed that TLR4 and MyD88 were up-regulated in necroptotic astrocytes after SCI and M1 CM could increase the expression of TLR2, TLR4 and MyD88 in astrocytes. Previous researches have reported that TLR4 is involved in the necroptosis of macrophages in vitro and in the activation of astrocytes after SCI [40, 41]. These results indicated that M1 microglia/macrophages may induce the necroptosis of astrocytes by activating TLR4/MyD88 signaling. In consistent, inhibiting MyD88 could partially block the necroptosis-inducing effect of M1 microglia/macrophages in vitro. In addition, the expression of TLR4/ MyD88 in human necroptotic astrocytes indicated a common response of this signaling pathway after SCI. Considering that MyD88 mediates the downstream signals of 
multiple TLRs, and TLZ stimulates both the expression of TLR2 and TLR4 in vitro, the involvement of other TLRs in the M1 microglia/macrophages-induced astrocytic death is not excluded. It has been demonstrated that necroptotic cells release factors that modulate inflammation [42], whether necroptotic astrocytes could regulate the chronic inflammation after SCI is of interest to be further investigated.

As the major component of glial scar, reactive astrocytes exhibit heterogeneous properties and exert multifaceted functions in SCI, such as providing nutritive and metabolic support for neurons, inhibiting axonal growth and modulating inflammation [43, 44]. Our data showed that necroptotic astrocytes were less supportive for neuronal survival, and inhibiting astrocytic necroptosis could rescue the neurotrophic function of reactive astrocytes, thereby reducing cavity area and promoting the survival of neurons surrounding lesion center which otherwise underwent apoptosis during the secondary injury $[45,46]$. It is still unknown how the properties of reactive astrocytes change when necroptotic signaling is activated. Nevertheless, our data, for the first time, have revealed a novel mechanism for the astrocytic death after SCI, implying that astrocytic necroptosis may be manipulated for preventing secondary $\mathrm{SCI}$ in the future.

\section{Conclusions}

After SCI, cavity-surrounding reactive astrocytes undergo RIP3/MLKL-mediated necroptosis, rather than apoptosis and autophagy. The necroptosis of astrocytes is induced by M1 microglia/macrophages, partially through TLR/ MyD88 signaling. Reactive astrocytes in injured human spinal cord die through similar mechanism. Our data suggested that inhibiting astrocytic necroptosis may be beneficial for preventing secondary SCI.

\section{Methods}

Animals and human samples

$\mathrm{RIP3}^{-/-}$mice were generated as described [47]. GFAPCreER and ROSA-YFP mice were bought from Jackson laboratory. Wild-type mice were bought from the animal center of the Fourth Military Medical University. All protocols of animal experiments were approved by the Animal Care and Use Committee of the Fourth Military Medical University.

Snap-frozen normal human spinal cord tissues were obtained from human brain bank of school of medicine at Zhejiang University. Biopsy of injured spinal cord tissues were performed with informed consent obtained from each patient prior to surgery and experiments involving human spinal tissues were approved by the Institutional Review Board of Tangdu Hospital, Fourth Military Medical University.

\section{Reagents}

Necrostatin-1 was bought from Tocris. Propidium iodide, DCFH-DA, $\mathrm{GdCl}_{3}$ and LPS were bought from Sigma. ATP detecting and TUNEL staining kits were from Promega. LPS, z-VAD and human TNFa were from R \& D system. IFN- $\gamma$ and IL-4 were from Peprotech. The source and dilution of antibodies were included in Table 1.

\section{Spinal cord contusion and in vivo treatments}

C57 mice of 25-30 g were anesthetized with $1 \%$ sodium pentobarbital. For improving the consistency of the experimental data, W. Tazlaff developed a manual graded forceps lateral crush SCI model [48]. Because it is difficult for manual performance to ensure vertical orientation of the forceps and equal degree of compression of the two sides of the cord, we designed a mechanical version by mounting a pair of forceps on a stereotaxic device, and thereby its two blades could be closed simultaneously from both sides [14]. Briefly, a 15-30 mm dorsal midline incision was made by bilateral laminectomy. Spinal cord injury was made at $\mathrm{T} 8$ vertebra (corresponding to T9 segment of the spinal cord) by lateral crushing, setting the gap between the blades of the forceps at $0.2 \mathrm{~mm}$ for $15 \mathrm{~s}$.

Table 1 Information for primary antibodies used

\begin{tabular}{|c|c|c|c|}
\hline Antibodies & Hosts & Dilutions & Sources \\
\hline Anti-Arginase1 & Goat & IHC 1:50, WB 1:200 & Santa Cruz \\
\hline Anti-Beclin1 & Mouse & IHC 1:200, WB 1:500 & Cell Signaling \\
\hline Anti- $\beta$-actin & Mouse & WB 1:50000 & Sigma \\
\hline Anti-CC1 & Mouse & $\mathrm{IHC1:500}$ & Millipore \\
\hline \multirow[t]{2}{*}{ Anti-GFAP } & Mouse & IHC1:500 & Millipore \\
\hline & Rabbit & $\operatorname{HC1:1000}$ & Dako \\
\hline Anti-HMGB1 & Rabbit & IHC 1:100, WB 1:500 & Proteintech \\
\hline Anti-iNOS & Mouse & IHC 1:200, WB 1:500 & $\mathrm{BD}$ \\
\hline Anti-Lamp2a & Rabbit & IHC1:200 & Abcam \\
\hline Anti-LC3 & Mouse & $\mathrm{IHC1:500}$ & Cell Signaling \\
\hline Anti-MLKL & Rat & IHC 1:200, WB 1:500 & Millipore \\
\hline anti-pMLKL & Rabbit & IHC1:300 & Abcam \\
\hline Anti-MyD88 & Rabbit & IHC 1:50, WB 1:200 & Abcam \\
\hline Anti-NeuN & Mouse & $\mathrm{IHC1:500}$ & Millipore \\
\hline Anti-OX42 & Mouse & IHC1:200 & Abcam \\
\hline \multirow[t]{2}{*}{ Anti-RIP3 } & Rabbit & IHC 1:200, WB 1:500 & Enzo \\
\hline & Rabbit & WB 1:500 & Abcam \\
\hline Anti-TLR2 & Rabbit & IHC1:100, WB 1:200 & EPITOMICS \\
\hline Anti-TLR4 & Mouse & IHC 1:200, WB 1:500 & Abcam \\
\hline Anti-YFP & Goat & $\mathrm{IHC1:600}$ & Rockland \\
\hline
\end{tabular}




\section{In vivo Propidium iodide (PI) staining}

PI $(10 \mathrm{mg} / \mathrm{ml})$ was diluted in $0.9 \% \mathrm{NaCl}$. Twenty $\mathrm{mg} / \mathrm{kg}$ of PI in a total volume of not more than $100 \mu \mathrm{l}$ was administered (i.p.) to mice $1 \mathrm{~h}$ before sacrifice as described $[49,50]$.

\section{Nec-1 administration}

Nec-1 $(7.8 \mathrm{mg} / \mathrm{kg})$ was administrated intravenously (i.v.) twice a day for 5 or 7 days (5 days for examining the expression of necroptotic markers, and 7 days for evaluating cavity size and locomotion recovery).

\section{Genetic astrocyte labeling}

Tamoxifen $(2.5 \mathrm{mg})$ in corn oil was administered from 7 days before SCI for five successive days (Fig. 1b).

\section{M1 microglia/macrophages depletion}

One day after $\mathrm{SCI}, \mathrm{GdCl}_{3}(270 \mu \mathrm{M})$ was injected into the lesion area as described [25]. Three injections were made, one in the lesion center, two at $2 \mathrm{~mm}$ rostral or caudal to the epicenter, respectively. The volume of each injection is $1.5 \mu$ l. The efficiency of depletion was confirmed 3 days after injection by western-blotting of iNOS.

\section{M1 macrophages transplantation}

Immediately after SCI, a total of $2 \times 10^{6} \mathrm{M} 1, \mathrm{M} 0$ microglia in $2 \mu \mathrm{l}$, or same volume of Dulbecco's modified Eagle's medium (DMEM) was injected into the lesion center.

\section{Behavior evaluation}

The Basso Mouse Scale (BMS) was used to rate locomotor function and recovery by two investigators blinded to the experimental design.

\section{Cell culture and in vitro treatments}

\section{Astrocyte culture, purification and treatments}

Mice at postnatal day 2-4 were freeze anesthetized, and skin sterilized with $75 \%$ alcohol. The brain was removed under a stereomicroscope. The cortex was dissected and meninges peeled off. The tissue was digested in $0.125 \%$ trypsin for $10 \mathrm{~min}$ at $37{ }^{\circ} \mathrm{C}$ and the digestion was stopped by adding $10 \%$ fetal bovine serum (FBS) in DMEM. After centrifuging at $800 \mathrm{rpm}$ for $5 \mathrm{~min}$, the cell suspension was moved to $75 \mathrm{~cm}$ flasks pre-coated with poly-D-lysine and cultured in DMEM containing $10 \%$ FBS at $37{ }^{\circ} \mathrm{C}$ with $5 \% \mathrm{CO}_{2}$. Culture medium was half changed every other day.

Astrocytes were purified as described with modifications [21, 22]. When cells reached confluence, the culture was purified by shaking at $260 \mathrm{rpm}$ overnight, and the suspended microglia and oligodendrocytes were discarded. The cells were then cultured with $8 \mu \mathrm{M}$ arabinoside $\mathrm{C}$ (Ara $\mathrm{C}$ ) for 3 days, followed by a $1 \mathrm{~h}$ l-leucine methyl ester (LME, $60 \mu \mathrm{M}$ ) treatment. This cell shaking, passaging, Ara $\mathrm{C}$ and LME treatment were repeated once. Immunocytochemistry of GFAP, Sox10 and CD11b was performed to evaluate the purity of astrocytes. Only batches of cells with GFAP-positive cells over $99 \%$ were used for cell death induction.

For necroptosis induction, TNF $\alpha$ (100 ng/ml), LPS $(4 \mu \mathrm{g} / \mathrm{ml})$ and $\mathrm{z}$-VAD $(20 \mu \mathrm{M})$ were used according to literatures $[23,51,52]$ and our preliminary experiments, and added to the culture medium for $48 \mathrm{~h}$. For collecting CM from necroptotic astrocytes, TLZ was washed off before fresh serum-free medium was added. And then $\mathrm{CM}$ was collected $24 \mathrm{~h}$ later. For necroptosis inhibition, Necrostatin-1 (20 $\mu \mathrm{M})$ was added together with TNF $\alpha$, LPS and z-VAD (TLZ) stimulation. For interfering with TLR4/MyD88 signaling, MyD88 inhibitory peptide $(100 \mu \mathrm{M}$, Novas, Cat. NBP2-29328) was added into medium $8 \mathrm{~h}$ before TLZ treatment.

\section{Micoglia culture and treatments}

When primarily cultured astrocytes reach confluency, cells were shaken at $260 \mathrm{rpm}$ for $30 \mathrm{~min}$. The cells in the suspension were collected and re-plated. The purity of microglia was confirmed by immunostaining of CD11b. For inducing M1 microglia, cells were treated with LPS (100 ng/ml) plus IFN- $\gamma(20 \mathrm{ng} / \mathrm{ml})$ for $24 \mathrm{~h}$. For M2 polarization, cells were treated with IL-4 (20 ng/ $\mathrm{ml}$ ) for $24 \mathrm{~h}$. Then stimulators were removed and medium refreshed for $24 \mathrm{~h}$ before collecting conditioned medium. The normal cultured microglia (M0) received no treatment except regular medium refreshment.

\section{Spinal cord neuron culture and treatments}

Spinal cords were dissected from E12-13 mice embryos. The dorsal root ganglions and meninges were carefully peeled off. The tissue was digested in $0.125 \%$ trypsin for $10 \mathrm{~min}$ at $37^{\circ} \mathrm{C}$ and the digestion was stopped by adding $10 \%$ fetal bovine serum (FBS) in Neurobasal. After centrifuging at $700 \mathrm{rpm}$ for $6 \mathrm{~min}$, the cell suspension was moved to $25 \mathrm{~cm}$ culture dishes pre-coated with poly-Dlysine and cultured in Neurobasal containing $1 \%$ N2 supplement and $8 \mu \mathrm{M}$ Ara C. Forty-eight hours later, Ara C was washed off, and neurons cultured with Neurobasal containing $1 \% \mathrm{~N} 2$. Culture medium was half changed every other day.

Seven days after culture, neurons were cultured with conditioned medium from TLZ treated astrocytes or control astrocytes for $24 \mathrm{~h}$. TUNEL staining was then performed for assessing cell death.

\section{Bone marrow macrophage culture and treatment}

Bone marrow cells were collected from the femurs and tibias of mice by trituration using 26-gauge needles. Red blood cells were lysed by lysis buffer containing $0.15 \mathrm{M}$ $\mathrm{NH}_{4} \mathrm{Cl}, 10 \mathrm{nM} \mathrm{KHCO}_{3}$, and $0.1 \mathrm{mM}$ EDTA (pH7.4). 
After washing with RPMI 1640, the cells were cultured in RPMI 1640 supplemented with $1 \%$ penicillin/ streptomycin, 1 \% 4-(2-hydroxyethyl) piperazine-1ethanesulfonic acid, $0.1 \% \beta$-mercaptoethanol, $10 \%$ FBS, and $20 \%$ sL929-conditioned medium containing macrophage colony-stimulating factor (M-CSF). After 7-10 days culture, nonadherent cells were removed. Adherent cells were treated with LPS $(100 \mathrm{ng} / \mathrm{m})$ and IFN- $\gamma(20 \mathrm{ng} / \mathrm{ml})$ for M1 polarization, or with IL-4 (20 $\mathrm{ng} / \mathrm{ml}$ ) for M2 polarization. Twenty-four hours later, the stimulators were removed and medium refreshed before collecting conditioned medium. The normal cultured macrophages were considered as M0 macrophages.

\section{Immunohistochemistry}

Animals were sacrificed and perfused intracardially with $4 \%$ cold paraformaldehyde phosphate buffer $(\mathrm{pH} 7.4)$. Following perfusion, a $2 \mathrm{~cm}$ spinal cord segment with the lesion site at its center was removed and cryoprotected by $25 \%$ sucrose. For each mice, serial sections (20 $\mu \mathrm{m}$ in thickness for each section) were cut and all the sections were collected onto eight slides. Among these eight slides, only 2-3 slides contain one section which was cut through central canal. For immunostaining, the sections were blocked by $0.01 \mathrm{M}$ phosphate buffered saline (PBS) containing $0.3 \%$ Triton X-100 and $3 \%$ bovine serum albumin (BSA) for $1 \mathrm{~h}$. Primary antibodies (as described in Table 1) were incubated at room temperature overnight. After washing with PBS, sections were incubated with their corresponding secondary antibodies conjugated with Alexa Fluor 594 (donkey anti-rabbit or anti-rat IgG, 1:800, Molecular probes), Alexa Fluor 488 (donkey anti-mouse, 1:500, Molecular probes) or Alexa Fluor 680 (donkey anti-rabbit IgG, 1:1000, Molecular probes) for $4 \mathrm{~h}$ at room temperature protected from light. The nuclei were counterstained by Hoechst33342 (1:5000, Sigma). All immunostained sections were photographed under a confocal microscope (FV1000, Olympus) with same setting. 3-D reconstruction was made using IMARIS software.

Quantification of the immunostaining in injured spinal cord was performed as described [14, 53, 54]. One of the slides which contain the section cut through central canal was randomly chose for immunostaining, and all the sections on this slide were subjected to quantification. The lesion area was defined by the inner lining of GFAP stained astrocytes. After outlining the injury epicenter, the borderline was shifted $400 \mu \mathrm{m}$ rostrally and caudally respectively (Fig. 1c). The resulting areas from shifting were calculated by converting the pixels into millimeters by using Image J. All the immunopositive cells within the defined area were counted by using ImagePro Plus Version 5.0. The slide selection and cell counting were performed by an investigator who was blind to experimental design.

\section{TUNEL staining}

For TUNEL/GFAP double-staining, TUNEL staining was performed first according to the manual of DeadEND TUNEL system (Promega), and then followed by immunostaining of GFAP.

\section{Immuno-electron microscopy}

The immune-electron microscopic study was performed as described [55]. Briefly, at 5d after SCI, the mice were perfusion fixed with a mixture of $4 \%$ paraformaldehyde, $0.05 \%$ glutaraldehyde, and $15 \%$ saturated picric acid for $30 \mathrm{~min}$. Then injured spinal cords were removed and postfixed in the same fixative without glutaraldehyde for $3 \mathrm{~h}$. Tissue sections of $50 \mu \mathrm{m}$ were prepared with a vibratome and cryoprotected by $30 \%$ sucrose. After one freezethaw treatment, the sections were blocked by $5 \%$ bovine serum albumin and $5 \%$ normal goat serum, incubated with anti-RIP3 or MLKL antibodies, and then with goat antirabbit or anti-rat IgG conjugated to $1.4 \mathrm{~nm}$ gold particles (1:100, Nanoprobes) at room temperature overnight sequentially. After rinsing, the sections were postfixed with $2 \%$ glutaraldehyde for $45 \mathrm{~min}$. Silver enhancement was performed in the dark with an HQ Silver Kit (Nanoprobes). The sections were further fixed with $0.5 \%$ osmium tetroxide, dehydrated with graded ethanol, replaced with propylene oxide, and flat-embedded in Epon 812. The RIP3- and MLKL-immunoreactive areas surrounding lesion center were selected, trimmed under a stereomicroscope and mounted onto blank resin stubs for ultrathin sectioning. Ultrathin sections (70-80 nm) were prepared on an LKB Nova Ultratome (Bromma). After being counterstained with uranyl acetate and lead citrate, the sections were examined under a JEM-1230 electron microscope (JEM, Tokyo).

\section{Western blot analysis}

The spinal cord segments with lesion at their center were dissected out. Each sample was homogenized in RIPA buffer for about $20 \mathrm{~min}$ and incubated for another $40 \mathrm{~min}$ on ice, then centrifuged at $12000 \mathrm{~g}$ at $4{ }^{\circ} \mathrm{C}$. Supernatant was boiled before sodium dodecyl sulfate polyacrylamide gel electrophoresis. The proteins were electrotransferred to polyvinylidene difluoride membrane and reacted with primary antibodies ( as described in Table 1) overnight at $4{ }^{\circ} \mathrm{C}$, then with corresponding secondary anti-mouse, anti-rabbit, or anti-rat IgGperoxidase (1:5000) at room temperature for $50 \mathrm{~min}$. The bands were visualized by an ECL kit (Millipore). 


\section{In vitro PI-staining, ROS and ATP measurement Live cell PI labeling}

PI $(5 \mu \mathrm{M})$ and Hoechst $33342(5 \mu \mathrm{g} / \mathrm{ml})$ were added into the culture medium and incubated for $30 \mathrm{~min}$ at $37{ }^{\circ} \mathrm{C}$. Cells were then washed three times with $0.01 \mathrm{M}$ PBS and fixed with $4 \%(\mathrm{w} / \mathrm{v})$ paraformaldehyde in $\mathrm{PB}$ for $10 \mathrm{~min}$ at room temperature and then imaged under an inverted fluorescence microscope (IX71, Olympus) equipped with an Olympus DP72 digital camera.

\section{ROS measurement}

Oxidation-sensitive fluorescent probe DCFH-DA was adopted to evaluate ROS levels. Astrocytes were cultured in 96-well plates. DCFH-DA $(10 \mu \mathrm{M})$ was added and incubated for $20 \mathrm{~min}$ at $37^{\circ} \mathrm{C}$. After washing with PBS, the ROS levels were determined by a multimode microplate reader (TECAN, infinite M200), and images were photographed under an inverted fluorescence microscope (IX71, Olympus).

\section{ATP measurement}

Intracellular levels of ATP were measured using the Cell Titer-Glo luminescent cell viability assay kit (Promega) according to the manufacturer's instructions. Luminescence was measured by multimode microplate reader (TECAN, infinite M200).

\section{Statistical analysis}

For each of triplicate in vitro experiments, pictures were taken from eight random fields. All cells in the images were analyzed. Image Tool (University of Texas Health Sciences Center at San Antonio) was used for quantification.

The data were presented as means \pm S.E., and analyzed by one-way ANOVA, followed by Dunnett post hoc, except for BMS scoring which was further analyzed by Bonferroni post hoc using SPSS16.0 (Chicago, IL, USA) as recommended [56]. $P$ values less than 0.05 were considered as statistical significant.

\section{Additional files}

Additional file 1: Figure S1. Double-staining of GFAP with Sox10 and CD11b after astrocyte purification. Over $99 \%$ of cells were GFAP-positive. Very rare could Sox10- and CD11b-positive cells be detected. Bar $=15 \mu \mathrm{m}$. (TIF $2385 \mathrm{~kb}$ )

Additional file 2: Figure S2. Western-blotting of iNOS and Arginase 1 in M1 and M2 polarized micoglia and macrophages. (TIF $1374 \mathrm{~kb}$ )

Additional file 3: Figure S3. Western-blotting and quantification of RIP3, MLKL and HMGB1 in astrocytes treated by conditioned medium from M0 microglia (M0 CM), M1 microglia (M1 CM), and M2 microglia (M2 CM). Notice that $\mathrm{M} 1 \mathrm{CM}$ has the strongest effects in stimulating the expression of RIP3, MLKL and HMGB1. ${ }^{*} P<0.05,{ }^{*} P<0.01 . n=3$. (TIF $3027 \mathrm{~kb}$ )

Additional file 4: Figure S4. Western-blotting of iNOS at $5 \mathrm{dpi}$ in $\mathrm{GdCl}_{3}$ or PBS treated mice. The expression of iNOS was reduced in $\mathrm{GdCl}_{3}$ treated mice. ${ }^{*} P<0.05 . n=3$. (TIF $87 \mathrm{~kb}$ )
Additional file 5: Figure S5. Western-blotting of TLR2 in purified astrocytes after TLZ treatment. (TIF $325 \mathrm{~kb}$ )

\section{Abbreviations}

Ara C: Arabinoside C; BSA: Bovine serum albumin; CC3: Cleaved Caspase-3; CM: Conditioned medium; DMEM: Dulbecco's modified eagle's medium; dpi: Days post-injury; EM: Electronic microscopic; FBS: Fetal bovine serum; GdCl3: Gadolinium chloride; GDNF: Glial cell line-derived neurotrophic factor; GFAP: Glial fiber acid protein; HMGB1: High mobility group box protein 1; IDO: Indoleamine-2,3-dioxygenase; iNOS: Inducible nitric oxide synthase; LME: I-leucine methyl ester; LPS: Lipopolysaccharide; M-CSF: Macrophage colony-stimulating factor; MLKL: Mixed lineage kinase domain-like protein; MyD88: Myeloid differentiation primary response gene 88; Nec-

1: Necrostatin-1; PBS: Phosphate buffered saline; PI: Propidium iodide; RIP1: Receptor-interacting protein 1; RIP3: Receptor-interacting protein 3; ROS: Reactive oxygen species; SCl: Spinal cord injury; TLR4: Toll-like receptor 4; TLZ: TNFa, LPS and Z-VAD; TLZN: TLZ plus Nec-1; TNFa: Tumor necrosis factor alpha.

\section{Competing interests}

The authors declare that they have no competing interests.

\section{Authors' contributions}

HF performed most experiments, collected and analyzed data, and wrote the paper. KZ contributed to cell culture. KC contributed to morphological quantification. SL and KZ contributed to analysis of human spinal tissues. FK contributed to TLR/MyD88 study. HM contributed to the studies of RIP3 ${ }^{-/}$ mice. GJ and YW designed the experiments, analyzed data, provided financial support and wrote the paper. All authors read and approved the final manuscript.

\section{Acknowledgments}

This work was supported by grants from the National Natural Science Foundation of China (NSFC, 81571224, 31271583,) to Dr. Ya-Zhou Wang, NSFC (81371364) to Dr. Gong Ju, and NSFC (81272072) to Dr. Lequn Shan. And research fellowship from Fourth Military Medical University (2013D09) to Dr. Hong Fan. The RIP3 ${ }^{-1-}$ mice were received from Dr. Dixit at Genentech. We appreciate the technical assistances from Drs. Junjun Kang, Jialei Yang and Haifeng Zhang. The authors thank Drs. Biswas Sangita, Fuzheng Guo and Wenbin Deng (University of California at Davis) for language editing.

\section{Author details}

${ }^{1}$ Department of Neurobiology and Collaborative Innovation Center for Brain Science, School of Basic Medicine, Fourth Military Medical University, Xi'an 710032, China. ${ }^{2}$ Department of Orthopedics, Tangdu Hospital, Fourth Military Medical University, Xin Si Road, Xi'an, Shaanxi 710038, China. ${ }^{3}$ Zhejiang University China Brain Bank, Department of Pathology and Pathophysiology, Department of Neuroscience, 866 Yu-Hang-Tang Road, Zhejiang University Zi-Jin-Gang Campus, Hangzhou, Zhejiang 310058, China. ${ }^{4}$ Department of Physiology \& Department of Pathophysiology, School of Basic Medical Sciences, Fourth Military Medical University, 169 Chang Le Xi Road, Xi'an, Shaanxi 710032, China.

Received: 22 July 2015 Accepted: 29 January 2016 Published online: 03 February 2016

\section{References}

1. Schwab JM, Zhang Y, Kopp MA, Brommer B, Popovich PG. The paradox of chronic neuroinflammation, systemic immune suppression, autoimmunity after traumatic chronic spinal cord injury. Exp Neurol. 2014;258:121-9.

2. Ju G, Wang J, Wang Y, Zhao X. Spinal cord contusion. Neural Regen Res. 2014;9:789-94.

3. Lu J, Ashwell KW, Waite P. Advances in secondary spinal cord injury: role of apoptosis. Spine (Phila Pa 1976). 2000;25:1859-66.

4. Park E, Velumian AA, Fehlings MG. The role of excitotoxicity in secondary mechanisms of spinal cord injury: a review with an emphasis on the implications for white matter degeneration. J Neurotrauma. 2004;21:754-74.

5. Beattie MS, Hermann GE, Rogers RC, Bresnahan JC. Cell death in models of spinal cord injury. Prog Brain Res. 2002;137:37-47. 
6. Karimi-Abdolrezaee S, Billakanti R. Reactive astrogliosis after spinal cord injury-beneficial and detrimental effects. Mol Neurobiol. 2012;46:251-64.

7. Fitch MT, Doller C, Combs CK, Landreth GE, Silver J. Cellular and molecular mechanisms of glial scarring and progressive cavitation: in vivo and in vitro analysis of inflammation-induced secondary injury after CNS trauma. J Neurosci. 1999;19:8182-98.

8. de Rivero Vaccari JP, Minkiewicz J, Wang X, De Rivero Vaccari JC, German R, Marcillo $A E$, et al. Astrogliosis involves activation of retinoic acid-inducible gene-like signaling in the innate immune response after spinal cord injury. Glia. 2012;60:414-21.

9. David S, Kroner A. Repertoire of microglial and macrophage responses after spinal cord injury. Nat Rev Neurosci. 2011;12:388-99.

10. Wang X, Cao K, Sun X, Chen Y, Duan Z, Sun L, et al. Macrophages in spinal cord injury: phenotypic and functional change from exposure to myelin debris. Glia. 2015:63:635-51.

11. Kroner A, Greenhalgh AD, Zarruk JG, Passos Dos Santos R, Gaestel M, David S. TNF and increased intracellular iron alter macrophage polarization to a detrimental M1 phenotype in the injured spinal cord. Neuron. 2014;83:1098-116.

12. Kigerl KA, Gensel JC, Ankeny DP, Alexander JK, Donnelly DJ, Popovich PG. Identification of two distinct macrophage subsets with divergent effects causing either neurotoxicity or regeneration in the injured mouse spinal cord. J Neurosci. 2009;29:13435-44.

13. Christofferson DE, Yuan J. Necroptosis as an alternative form of programmed cell death. Curr Opin Cell Biol. 2010;22:263-8.

14. Fan H, Liu X, Tang HB, Xiao P, Wang YZ, Ju G. Protective effects of Batroxobin on spinal cord injury in rats. Neurosci Bull. 2013;29:501-8.

15. Liu K, Lu Y, Lee JK, Samara R, Willenberg R, Sears-Kraxberger I, et al. PTEN deletion enhances the regenerative ability of adult corticospinal neurons. Nat Neurosci. 2010;13:1075-81.

16. Sun L, Wang X. A new kind of cell suicide: mechanisms and functions of programmed necrosis. Trends Biochem Sci. 2014;39:587-93.

17. Zhang DW, Shao J, Lin J, Zhang N, Lu BJ, Lin SC, et al. RIP3, an energy metabolism regulator that switches TNF-induced cell death from apoptosis to necrosis. Science. 2009;325:332-6.

18. Sun L, Wang H, Wang Z, He S, Chen S, Liao D, et al. Mixed lineage kinase domain-like protein mediates necrosis signaling downstream of RIP3 kinase. Cell. 2012;148:213-27.

19. Scaffidi P, Misteli T, Bianchi ME. Release of chromatin protein HMGB1 by necrotic cells triggers inflammation. Nature. 2002;418:191-5.

20. Wang H, Sun L, Su L, Rizo J, Liu L, Wang LF, et al. Mixed lineage kinase domain-like protein MLKL causes necrotic membrane disruption upon phosphorylation by RIP3. Mol Cell. 2014;54:133-46.

21. Gingras M, Gagnon V, Minotti S, Durham HD, Berthod F. Optimized protocols for isolation of primary motor neurons, astrocytes and microglia from embryonic mouse spinal cord. J Neurosci Methods. 2007;163:111-8.

22. Hamby ME, Uliasz TF, Hewett SJ, Hewett JA. Characterization of an improved procedure for the removal of microglia from confluent monolayers of primary astrocytes. J Neurosci Methods. 2006;150:128-37.

23. Degterev A, Huang Z, Boyce M, Li Y, Jagtap P, Mizushima N, et al. Chemical inhibitor of nonapoptotic cell death with therapeutic potential for ischemic brain injury. Nat Chem Biol. 2005;1:112-9.

24. Vandenabeele P, Grootjans S, Callewaert N, Takahashi N. Necrostatin-1 blocks both RIPK1 and IDO: consequences for the study of cell death in experimental disease models. Cell Death Differ. 2013;20:185-7.

25. Miron VE, Boyd A, Zhao JW, Yuen TJ, Ruckh JM, Shadrach JL, et al. M2 microglia and macrophages drive oligodendrocyte differentiation during CNS remyelination. Nat Neurosci. 2013;16:1211-8.

26. Mizgerd JP, Molina RM, Stearns RC, Brain JD, Warner AE. Gadolinium induces macrophage apoptosis. J Leukoc Biol. 1996;59:189-95.

27. Hardonk MJ, Dijkhuis FW, Hulstaert CE, Koudstaal J. Heterogeneity of rat liver and spleen macrophages in gadolinium chloride-induced elimination and repopulation. J Leukoc Biol. 1992;52:296-302.

28. Ransohoff RM, Brown MA. Innate immunity in the central nervous system. J Clin Invest. 2012;122:1164-71.

29. Heiman A, Pallottie A, Heary RF, Elkabes S. Toll-like receptors in central nervous system injury and disease: a focus on the spinal cord. Brain Behav Immun. 2014;42:232-45.

30. Uto T, Wang X, Sato K, Haraguchi M, Akagi T, Akashi M, et al. Targeting of antigen to dendritic cells with poly(gamma-glutamic acid) nanoparticles induces antigen-specific humoral and cellular immunity. J Immunol. 2007;178:2979-86
31. Profyris C, Cheema SS, Zang D, Azari MF, Boyle K, Petratos S. Degenerative and regenerative mechanisms governing spinal cord injury. Neurobiol Dis. 2004;15:415-36.

32. Newton K. RIPK1 and RIPK3: critical regulators of inflammation and cell death. Trends in cell biology 2015;25:347-353.

33. de Almagro MC, Vucic D. Necroptosis: pathway diversity and characteristics. Semin Cell Dev Biol. 2015;39:56-62.

34. Wang $Y$, Wang $H$, Tao $Y$, Zhang S, Wang J, Feng X. Necroptosis inhibitor necrostatin-1 promotes cell protection and physiological function in traumatic spinal cord injury. Neuroscience. 2014;266:91-101.

35. Wang $Y$, Wang J, Yang H, Zhou J, Feng X, Wang H, et al. Necrostatin-1 mitigates mitochondrial dysfunction post-spinal cord injury. Neuroscience. 2015;289:224-32.

36. Fan $H$, Tang HB, Kang J, Shan L, Song H, Zhu K, Wang J, Ju G, Wang YZ: Involvement of endoplasmic reticulum stress in the necroptosis of microglia/ macrophages after spinal cord injury. Neuroscience 2015;311:362-373.

37. Zhou X, He X, Ren Y. Function of microglia and macrophages in secondary damage after spinal cord injury. Neural Regen Res. 2014;9:1787-95.

38. Strande JL, Routhu KV, Hsu A, Nicolosi AC, Baker JE. Gadolinium decreases inflammation related to myocardial ischemia and reperfusion injury. J Inflamm (Lond). 2009;6:34.

39. Garcia-Bonilla L, Moore JM, Racchumi G, Zhou P, Butler JM, ladecola C, et al. Inducible nitric oxide synthase in neutrophils and endothelium contributes to ischemic brain injury in mice. J Immunol. 2014;193:2531-7.

40. Kigerl KA, Lai W, Rivest S, Hart RP, Satoskar AR, Popovich PG. Toll-like receptor (TLR)-2 and TLR-4 regulate inflammation, gliosis, and myelin sparing after spinal cord injury. J Neurochem. 2007;102:37-50.

41. He S, Liang $Y$, Shao F, Wang X. Toll-like receptors activate programmed necrosis in macrophages through a receptor-interacting kinase-3-mediated pathway. Proc Natl Acad Sci U S A. 2011;108:20054-9.

42. Mayo L, Trauger SA, Blain M, Nadeau M, Patel B, Alvarez JI, et al. Regulation of astrocyte activation by glycolipids drives chronic CNS inflammation. Nat Med. 2014;20:1147-56.

43. Pekny M, Wilhelmsson $U$, Pekna $M$. The dual role of astrocyte activation and reactive gliosis. Neurosci Lett. 2014;565:30-8.

44. Anderson MA, Ao Y, Sofroniew MV. Heterogeneity of reactive astrocytes. Neurosci Lett. 2014;565:23-9.

45. Crowe MJ, Bresnahan JC, Shuman SL, Masters JN, Beattie MS. Apoptosis and delayed degeneration after spinal cord injury in rats and monkeys. Nat Med. 1997;3:73-6.

46. Liu XZ, Xu XM, Hu R, Du C, Zhang SX, McDonald JW, et al. Neuronal and glial apoptosis after traumatic spinal cord injury. J Neurosci. 1997;17:5395-406.

47. Newton K, Sun X, Dixit VM. Kinase RIP3 is dispensable for normal NF-kappa Bs, signaling by the B-cell and T-cell receptors, tumor necrosis factor receptor 1, and Toll-like receptors 2 and 4. Mol Cell Biol. 2004;24:1464-9.

48. Plemel JR, Duncan G, Chen KW, Shannon C, Park S, Sparling JS, et al. A graded forceps crush spinal cord injury model in mice. J Neurotrauma. 2008;25:350-70.

49. Oerlemans MI, Liu J, Arslan F, den Ouden K, van Middelaar BJ, Doevendans PA, et al. Inhibition of RIP1-dependent necrosis prevents adverse cardiac remodeling after myocardial ischemia-reperfusion in vivo. Basic Res Cardiol. 2012;107:270.

50. Ito WD, Schaarschmidt S, Klask R, Hansen S, Schäfer HJ, Mathey D, et al. Infarct size measurement by triphenyltetrazolium chloride staining versus in vivo injection of propidium iodide. J Mol Cell Cardiol. 1997;29:2169-75.

51. Tzeng SF, Kahn M, Liva S, De Vellis J. Tumor necrosis factor-alpha regulation of the Id gene family in astrocytes and microglia during CNS inflammatory injury. Glia. 1999;26:139-52.

52. Spina-Purrello V, Patti D, Giuffrida-Stella AM, Nicoletti VG. Parp and cell death or protection in rat primary astroglial cell cultures under LPS/IFNgamma induced proinflammatory conditions. Neurochem Res. 2008;33:2583-92.

53. Brennan FH, Gordon R, Lao HW, Biggins PJ, Taylor SM, Franklin RJ, et al. The complement receptor $\mathrm{C} 5 \mathrm{aR}$ controls acute inflammation and astrogliosis following spinal cord injury. J Neurosci. 2015;35:6517-31.

54. Schonberg DL, Goldstein EZ, Sahinkaya FR, Wei P, Popovich PG, McTigue DM. Ferritin stimulates oligodendrocyte genesis in the adult spinal cord and can be transferred from macrophages to NG2 cells in vivo. J Neurosci. 2012;32:5374-84.

55. Wang YZ, Liu YY, Liu JP, You SW, Ju G. Nogo-66 receptor at the gap junctions between pituicytes of the rat. Neuroreport. 2006;17:605-9.

56. Scheff SW, Saucier DA, Cain ME. A statistical method for analyzing rating scale data: the BBB locomotor score. J Neurotrauma. 2002;19:1251-60. 